\title{
Is Language the Result of a Necessity?
}

\author{
Franca Daniele \\ Department of Medical, Oral and Biotechnological Sciences \\ "G. d'Annunzio" University, Chieti - Pescara, Italy
}

Doi: 10.19044/esj.2017.v13n29p24 URL:http://dx.doi.org/10.19044/esj.2017.v13n29p24

\begin{abstract}
One of the most human characteristics is certainly language. Language is the means through which people communicate with each other both orally and in written form. Language represents one of the most important social behaviors, and thanks to language humans have been able to accumulate knowledge and transmit it from one generation to the next. The present paper will analyze how the human body has changed and evolved in response to the environmental solicitations and stimuli that have given origin to the development of a structured language, and parallel this with how, in turn, medical language has changed in the past years in response to social and cultural modifications.
\end{abstract}

Keywords: Language development, body changes, mouth, hand, medical language

\section{Introduction}

Language is certainly one of the most human characteristics. Indeed, humans are the only living organisms capable of using a structured set of signs and sounds that are collectively called language. Language is the means through which people communicate with each other both orally and in written form. Language represents one of the most important social behaviors, and thanks to language humans have been able to accumulate knowledge and transmit it from one generation to the next.

Nonetheless, all language capacities: talking, listening, reading and writing are extremely difficult to acquire, and do need a set of physicalbiological instruments and many crucial physiological mechanisms and processes. A number of factors have been involved with the development of language in man such as: 1) the brain in terms of both dimension and later, cerebral neuronal routes; and 2) the development of particular areas of the brain have been necessary for the acquisition of the ability to use a language (Deacon, 1997; Hurford, 1990; Kimura, 1993; Pinker, 2000). Also many bone structures have been involved with the development of languages. 
These include: the base of the skull, which seems to have undergone a flexion, the changes in the structure of the hyoid bone and in the dimension of the canal of the hypoglossal nerve (DeGusta, 1999). Of course the modifications of the form of the hands and the arms, and the fact that humans passed from a quadruped locomotion to an erect position have also been implicated. A particular role has been played by the mouth, the tongue and all other structures included in the mouth. A role seems to have been played by respiration and its control, which in turn, is under the control of the abdominal and thoracic muscles (Allott, 1989; Maclarnon, 1999).

It is important to highlight the fact that the acquisition of a language requires necessarily some type of interaction with the surrounding environment. Language learning needs elements capable of stimulating the components of the human body and new cerebral routes, which in turn, promote a better socio-biological adaptation and integration (Daniele, 2005; Hurford, 1990; Kolb, 2003). All memory processes including language acquisition are based on multiple experiences that result from multi-sensorial prompting. In order for stimulations to be multiple, they must by definition contain more than one stimulus. Thus, they have to necessarily contain a certain number of new elements, and such new elements themselves promote the language process that originates a thought, a form, and an interpretative key to reality (Daniele, 2005; Deacon, 1997; Kolb, 2003). Social systems can either inhibit or enhance the expression of some language latencies. Indeed, learning, any learning is actually the exposure to stimuli that are capable of either emphasizing or inhibiting such latencies through various levels of consciousness (Daniele, 2005; Kolb, 2003). Humans respond to the geography of the surrounding system, and in such a sense they reach a high language differentiation. This is also due to the complex interactions between humans and the environment, meaning by environment: everything and everyone capable of stimulating and producing a language experience. The building of a language is crucial for establishing complex mechanisms that are prearranged to reach refinement of conscience and emotions (Daniele, 2005; Kolb, 2003). The brain and the body as a whole have undergone important modifications in response to experience and to multiple stimuli, and thus the brain recognizes, synthesizes and integrates, leading to the creation of an individual form of language (Hauser, 2002; Pinker, 2000). A way for modifying such structures is through the activation of sensorial channels and the creation of new experiences. In such a context, 'language learning' represents the multiplication of cerebral stimulations that tend to transform central circuits such as synaptic contacts into even more and more entangled elements (Daniele, 2005).

Understanding of the complex modifications that have occurred throughout the years in man that represent the basis for reaching the complex 
level of language evolution might help all those professionals involved with teaching a foreign language in developing new strategies that support reaching of teaching goals more effectively. For these reasons, the present paper will first analyze how the human body has changed and evolved in response to the environmental solicitations and stimuli that have given origin to the development of a structured language, and then, it will parallel this with how, in turn, medical language has changed in the past years in response to social and cultural modifications.

\section{Why has the mouth replaced the hands?}

About 170,000 years ago, hominids probably began to develop a real non-oral communication system which was somewhat similar to the sign language used today by deaf people; while the shift to oral interaction came many years later. It seems that the selective pressures operated by the environment may have favored vocalization over gestures (Corballis, 2008; DeGusta, 1999). An advantage of oral communication is that words as opposed to gestures allow communication in the dark, so interactions can also occur at night. Moreover, another advantage of oral communication is that it allows bypassing of possible obstacles standing between the two interlocutors that prevent one from seeing the gestures. Another important function of language is certainly represented by the possibility to send out far away messages of warning and danger. So, the final acquisition of language through the voice has freed up the use of the hands, and thus all the necessary potential for manufacturing was made available. The development of a language skill such as talking has represented the discovery of some kind of technological tool, since an increasingly more complex amount of information could be described and transmitted. Accordingly, it is possible that language was born to give rise to an 'evolutionary burst', making human life so different from that of other animals, and the invention of a spoken language allowed the use of the hands for the creation of complex manufactures. In this way, language was no longer a manual task, enabling individuals to communicate while being engaged in other activities that required the use of the hands (Corballis, 2008).

\section{How Has The Mouth Replaced The Hands?}

Several studies have focused on the anatomy of our ancestors, showing that the larynx of the chimpanzee is structured in such a way as to make it physiologically impossible for them to scan consonants and vowels properly (de Waal, 2007; Deacon, 1997; DeGusta, 1999). The transition from the gesture system to the oral one covers a span of 70,000 years, and during this time, the ability to speak a language, in the course of evolution, has emerged very late (Wong, 2004). Language is believed to be an intrinsic 
characteristic of our species, and its acquisition is based on an innate grammatical capacity (Chomsky, 1965; Hauser, 2002). Others instead think that language learning is based on the utilization of various types of thoughts according to the person's culture, learning simple grammar sentences and later guessing the language rules (Deacon, 1997; Everett, 2005; Komarova, 2007). Furthermore, it must be stressed that the development of the ability to speak presupposes both anatomical and physiological modifications that could stand at the base of the switch from the emission of simple verses and groans to the ways humans became later capable of vocal articulations (Allott, 1989; Wong, 2004).

There has been primarily an increase in brain mass particularly in the cerebral cortex in terms of ratio between grey matter and white matter, and even more in the cerebral frontal lobes. On the other hand, the gradual increase in the size of the brain may, in turn, be partly due to the increase of man's dictionary (Deacon, 1997). Two main brain structures are involved with language: Broca's area is important for the production of spoken language, and Wernicke's area is necessary for language understanding (Deacon, 1997). These areas are closely connected to the regions involved with writing, reading and sign language, which are located in the left hemisphere (Kimura, 1993). Therefore, language is not only a consequence of the transition from gestures to oral language (from hand to mouth) but also from the mouth to the voice (Corballis, 2008). The neural network underlying oral memory tasks connects the posterior temporal neocortical regions to the frontal regions; the pre-motor cortex (area 6), the motor cortex, the supplementary motor area, and the prefrontal cortex are all involved (Allott, 1989). Structures such as the anterior cingulated cortex, the basal ganglia and other sub-cortical structures like the thalamus and the cerebellum perform crucial roles. The cortical and sub-cortical areas are part of the neural circuits involved with lexicon and with the production and perception of speech and syntax (Chomsky, 1965; Deacon, 1997). In particular, the basal ganglia cortico-subcortical circuits support the cortical-striatal circuits regulating the production of speech, complex syntax and the acquisition of motor and cognitive pattern generators that are the bases for speech production and syntax (Chomsky, 1965; Deacon, 1997). Most probably, they are also engaged in learning the semantic referents and sound patterns that are present in the dictionary of the brain as words (Pinker, 2000). The cerebellum and the prefrontal cortex are structures involved with learning of motor acts. The regions of the frontal cortex are the bases for almost all cognitive acts and the acquisition of cognitive criteria (Deacon,1997).

Knowledge of a word seems to reflect the conceptual knowledge stored in brain areas traditionally associated with visual perception and motor control (Pinker, 2000). Given the involvement of the basal ganglia in 
the cortico-striatal-cortical circuits that regulate upright bipedal locomotion, which is one of the first derivatives of hominid characteristics, adaptations aimed at improving locomotion may have started the processes that provided the neural basis of human linguistic abilities (Deacon, 1997; Kimura, 1993). Cortical neural circuits are implicated with the understanding of sentences, cognitive sequencing in speech and some aspects of motor control. The subcortical neuro-anatomical structures supporting populations of neurons that constitute these circuits also play a role in the regulation of emotions. The basal ganglia are critically involved with these circuits and implement at least three cognitive and motor control functions. The motor patterns generating the movements that produce human language seem to be learnt just like other acquired motor patterns. Also the cerebellum seems to be engaged in learning, and it may play a role in cognitive and linguistic activities that involve motor imagery (Allott, 1989).

It is very unlikely that a single factor can explain the evolution of language, because language skills arise from complex human neural bases. Indeed, the vocal tracts of humans have been compared with those of chimpanzees, showing distinct differences (Dunbar, 1996). Particularly in humans, refinement of the first bipedal posture and the fall of the foramen magnum favored above all inclination of the head and back, then shortening of the mandible occurred (Corballis, 2008; Deacon, 1997). All of these anatomical modifications have resulted in a lowering of the larynx in a deeper area of the throat. The primary functions of the anatomical components of the supra-laryngeal vocal tract such as the mouth, pharynx and throat are eating, swallowing and breathing, which are all necessary for human survival (DeGusta, 1999; Maclarnon, 1999).

Other organs playing a role in language production are the hypoglossal nerves and their respective canals. Since a different measure of the hypoglossal nerve corresponds to a different size of the hypoglossal canal, the extent of this latter reflects the number of nerve fibers in the hypoglossal nerve, so determining the fine innervation of the tongue, which acts as an index of the vocal skills in living species. Furthermore, tongue innervation and breath control have been probably necessary for the development of spoken language (DeGusta, 1999; Maclarnon, 1999).

A feature apparently required for the production of modern human speech that seems to have been more or less ignored in the discussion of language is the fine control of breathing and the sub-glottis air pressure that favor the production of sounds and perform some of their intricate variations. Breathing and the changes in air pressure both in the glottis and in the thoracic and abdominal cavities are controlled by the thoracic spinal nerves that supply: 1) the muscles of the chest wall; and 2) the muscles involved with human respiration like the diaphragm, the intercostal muscles, the 
internal and external abdominal muscles, the rectus abdominis, and the internal and external oblique muscles (Maclarnon, 1999). The increase in respiration neural control during human evolution seems to be the result of three main functional changes. In the first place, the evolution to the upright posture which has allowed the release of rhythmic breathing. Second, the increase in the functional evolution of breath control which has been necessary for the development of modern human speech and for eating; this is why mammals stop breathing while they swallow (Dunbar, 1996; Maclarnon, 1999). Third, phonation seems to have been also affected by the cyclical swinging of the jaw and the mouth during eating, their circular movements could be the basis of alternating opening and closing of the vocal tract (Maclarnon, 1999).

\section{Why have the hands replaced the mouth?}

In order to address this issue, it is important to understand that another 'evolutionary burst' or a 'revolutionary burst' has involved humans in the past years. Undoubtedly, all the technological communication means such as telephones, cell phones and the Internet have definitely devastated the ways people interact with each other. First, telephones have favored more prompt oral communications that can, just like for our ancestors, occur in the dark and at very long distances, so freeing up the hands that no longer have to write telegrams, letters and postcards. Later on cell phones appeared, which replaced traditional telephones, allowing not only immediate long distance oral communications, but also sending of short messages that can reach the interlocutor at anytime, anywhere in the world. So, although cell phones allow both oral and written communications, these latter seem to be more common and have had an immediate spread due to their low cost. More importantly, cell phones seem to be the communication means most used, over tablets and computers, to access the Internet for short messages. The worldwide spread of the Internet with its easiness and immediacy has taken charge over all other types of interactions, be them for work or for fun. The Internet has facilitated written communications over oral ones, so again using the hands and returning to that set of signs so dear to our ancestors. The Internet favors even the returning to images, which for our ancestors were represented by elementary drawings presenting the surrounding world and events; for us today, they are photos and sometimes even movies. As a consequence of the 'technological burst' a return to the hand from the mouth is occurring.

It is worth noting that similarly to our ancestors, today oral communications needing the use of the mouth, allow interactions in the dark and at limitless distances (Corballis, 2008; DeGusta, 1999). However, what is extremely interesting is that either when the two interlocutors are near 
each other or nearby as it occurred for our ancestors, or when the two interlocutors are in two different parts of the world as it occurs through phones and the Internet, oral communications are always an interaction. In other words, oral communications are two-way communications, they need the presence of two human beings sharing a set of sounds that can yield an effective oral exchange. During oral communication, the two parts involved must both be simultaneously active in order to produce an interaction. On the other hand, non-oral communications requiring the use of the hands can occur at any time, and can run across considerable distances; this was not possible for our ancestors (Corballis, 2008; DeGusta, 1999). Similarly to our ancestors, non-oral communications require a set of signs, which of course, today are more developed than the ones used by our ancestors. Such signs could be represented by either the articulated and organized written language, or by photos and other types of more or less complex systems of images produced by the most modern devices like photo- and video-cameras. Also, written communications are not two-way communications, they are no longer an interaction needing the presence of two human beings, instead interlocutors can access the messages at their convenience. Consistently, in this type of communication an interaction is not necessarily produced, since only one part is active while the other one passively receives written communications that might never be read!

In this context it is curious to note that in most of these interactions the English language is used both orally and in written form. So, the English language can be considered as a lingua franca, meaning: a language used for communication by two individuals whose native language is not the one they are using. Indeed, it expresses the magnitude and diffusion of a language endowed with 'freedom', and it has involved almost all languages before the popularization of the English language, but maybe as suggested elsewhere, today, it should probably be changed into lingua anglica. Nonetheless, the term franca could have been kept to somehow denote the frankness and straightforwardness of the English language, even though a language, any language, is always the result of the people who use it, or of the person who uses it (Daniele, 2004).

Worldwide, specific fields have also been pervaded by the English language almost with the same precise and targeted mechanism as that of a bacterium proliferating and damaging cells and organs. In medicine most communications occur in the English language and in written form, so somehow returning to a language system that includes a set of signs produced by the hands. Of course, this set of signs does not include gestures but actually the expressions of written language. These same processes are also triggered when communicating through a special language such as medical language. Many scientists increasingly denounce, with clear letters 
all the English language opprobrium we are forced to endure every time we open a medical journal and start reading an article (Daniele, 2004).

Nonetheless, more and more scientists need to communicate with each other, especially now that countries no longer possess boundaries. Actually, science more than any other field of man's knowledge has never really encountered boundaries, but still, more and more scientific discoveries need to be exchanged. However, scientists are not writers, and they are not linguists, and they have to write in English, which in most cases is not their native language. Thus, English medical language is practically always a lingua franca, because even when it is written or spoken by native English speakers it has good chances of being read or heard by non-native English speakers. In other words, even if the message is grammatically and linguistically expressed in an effective manner, it may be semantically interpreted and conceived in different ways by the different receivers. All this seems to somehow justify the mistakes and misuses of the English language in medical writings, and the 'higher end' of medical communication should eventually trigger greater tolerance by native English speakers! In sum, English language runs the risk of undergoing changes due to the contributions deriving from the different cultural patrimonies of the enormous number of people who use it (Daniele, 2004).

\section{CONCLUSION}

The present paper discusses the importance of feeling the necessity of a language in order to learn it, and how language expressions have evolved in response to man's needs. Differently from other species, the human mind with its richness and complexity has undergone outstanding modifications in order to respond to the necessity of constructing a language (Pinker, 2000). To this aim it is worthy to note how in the beginning language expressions were made up only by gestures (de Waal, 2007). Such gestures were supported by motor systems controlled by particular areas of the brain and by peripheral muscles located in the hands and the body as a whole (Allott, 1989). Later, humans underwent upright position in order to defend themselves from danger. Thus, with the passage from quadruped to upright locomotion, a set of changes also occurred in the throat, in the mouth and in the respiratory tract, which stimulated the production of primitive sounds that did not however correspond to a structured language yet (Corballis, 2008; Maclarnon, 1999). This latter appeared only after many, many years, and only after all these primitive sounds that could be called 'words' could be memorized and actually strikingly changed the dimensions of the brain. Indeed, memorizing words has caused the development of specific brain areas and dedicated neural circuits that could underlie the complex network 
of both neural and sensorial mechanisms and processes that represent the bases of any structured language (Kimura, 1993).

This 'evolutionary burst' has been followed by a 'technological burst' which has somehow forced man to return to the use of the hands to produce language, and to transmit knowledge from one generation to another. However, this time, language is not made up by a set of gestures but rather by a collection of signs that structure a complex and articulated design that is written language. Will Internet interactions and all the devices used to access it eventually change brain structures?

In more recent years, after Latin and German, the English language has become the language of science and medicine. Right from the beginning, the language of medicine has always been transmitted mainly in written form, and still today scientists and doctors from all over the world must communicate to each other through scientific articles published in scientific journals. Furthermore, they must communicate in English (Daniele, 2004). These two conventions (English and written form) stand at the base of any effective interaction and communication among doctors and scientists. Therefore, if doctors and scientists want to exchange their knowledge of medicine and science, they must learn how to write, and they must learn to do it in the English language. So again, learning of a language is a necessity. However, the resulting interactions do not always yield the correct forms of the language. Indeed, all the ready technological communication means and the simultaneous use of different languages always give rise to language anomalies. This phenomenon is somewhat similar to the expression of a new gene. However, the new gene may be either encoding for proteins that are necessary for the body because representing the physiological genetic evolution, or on the other hand, it may encode for proteins that bring some kind of perturbation to the normal genetic asset. In this latter case genetic anomalies result. This is presumably what languages are experiencing, and it seems that we are spectators of a movie playing in all languages, including not only medical language but also other registers and even standard languages (Daniele, 2004).

Perhaps we are destined to surrender to the natural course of the mutations that languages physiologically undergo as a consequence of economic, social and cultural, or intercultural and technological revolutions. Maybe it is true that languages do actually mirror all the modifications occurring in the world and to the world.

\section{References:}

1. Allott R. (1989) "The Motor Theory of Language Origin", Sussex, England, Book Guild. 
2. Amaral D.G. (1991) "Anatomical Organization of the Central Nervous System, in Kandel, Schwartz, Jessell, Elsevier, New York.

3. Bear M.F., Connors B.W., Paradiso M.A. (1999) "Neurosciences. Exploring the Brain", Masson Editore, Milano.

4. Burt A.M. (1996) "Neuroanatomy", Piccin Editore, Padova.

5. Cavalieri R. (2009) "Introduction to Language Biology", Editori Riuniti University Press, Roma.

6. Chomsky N. (1965) "Aspects of the Theory of Syntax", Cambridge, The MIT Press.

7. Corballis M.C. (2008) "Dalla Mano alla Bocca. Le Origini del Linguaggio", Cortina Raffaello Editore.

8. Daniele F. (2004) "We Certainly Do Pardon Proper English!" Merope, Ed. Tracce, Pescara, Vol. 43.

9. Daniele F. (2005) "Multiculturalism and Language Development", Merope, Ed. Tracce, Pescara, Vol. 44.

10. de Waal F.B.M. and Pollick A.S. (2007) "Ape Gestures and Language Evolution", PNAS, Vol. 104, No. 19, pp. 8184-9.

11. Deacon T.W. (1997) "The Symbolic Species: The Co-Evolution of Language and the Brain", New York, W.W. Norton.

12. DeGusta D., et al. (1999) "Hypoglossal Canal Size and Hominid Speech", PNAS Vol. 96, No. 4, pp. 1800-1804.

13. Dunbar R.I.M. (1996) "Grooming, Gossip and the Evolution of Language", London, Faber and Faber.

14. Everett D. (2005) "Cultural Constrains on Grammar and Cognition in Piraha", Current Anthropology, Vol. 46, No. 4, pp. 621-46.

15. Givón T. (2002) "The Evolution of Language out of Pre-Language, Typological Studies in Language", Amsterdam, John Benjamins, Vol. 53.

16. Harnad S.R., Lancaste, J.B. and Steklis H.D. (1976) "Origins and Evolution of Language and Speech", New York, N.Y., New York Academy of Sciences.

17. Hauser M.D., Chomsky N. and Fitch W. (2002) "The Faculty of Language: What Is It, Who Has It, and How Did It Evolve?" Science, Vol. 298, No. 5598, p. 1569.

18. Hurford J. (1990) "Nativist and Functional Explanations in Language Acquisition", in Roca I.M., Logical Issues in Language Acquisition, Foris, pp. 85-136.

19. Kandel E.R., Schwartz J.H., Dessel J. (2003) "Principles of Neurosciences", Casa Editrice Ambrosiana, Milano.

20. Kimura D. (1993) "Neuromotor Mechanisms in Human Communication”, Oxford, Oxford University Press. 
21. Kolb B. and Whishaw I.Q. (2003) "Fundamentals of Human Neuropsychology", 5th Edition, Worth Publishers.

22. Komarova N.L. (2007) "Language and Mathematics: An Evolutionary Model of Grammatical Communication", in History \& Mathematics. Ed. by Grinin L., de Munck V.C. and Korotayev A., Moscow, KomKniga/URSS, pp. 164-179.

23. Luria A.R. (1977) "How the Brain Works. Introduction to Neuropsychology" Il Mulino, Bologna.

24. Maclarnon A.M. and Hewitt G.P. (1999) "The Evolution of Human Speech: The Role of Enhanced Breathing Control", Am J of Physical Anthropology, Vol. 109.

25. Negus V.E. (1929) "The Mechanism of Larynx", Heinemann, London.

26. Noback C.N., Strominger R. (1996) "The Human Nervous System: Structure and Function", Williams \& Wilkins, USA.

27. Pinker S. (2000) "The Language Instinct: How the Mind Creates Language", New York, Harper Perennial Modern Classics, pp. 1314.

28. Wong Y. and Dawkins R. (2004) “The Ancestor's Tale: A Pilgrimage to the Dawn of Life", London, Weidenfeld \& Nicolson, pp. 36-87. 